a journey which he made last summer to Si-ning-fu and other almost unknown cities on the north-western frontier of the empire. After leaving the main road he travelled west to Hochow, and thence pushed along the border country to Shun-hwating on the bank of the Yellow River, crossing which he moved on to Ba-rung and thence to Si-ning-fu, where he stopped six days, returning by way of Lan-chow-fu. It may be interesting to note that many of the places visited by Mr. Easton are not marked on European maps, though he says they are shown on a Chinese map published in book form at Wu-chang. Near the Yellow River Mr. Easton found himself amongst the Sah-la, who differ little in appearance and habits from the Chinese, though they have an entirely distinct language; he also met a few Tu-ren-usually called the Tu-li tribe-who are also Mohammedans, and within a few miles of Si-ning-fu there are several other tribes. To his surprise, at Si-ning Mr. Easton found Count Bela Szechenyi, Lieut. Kreitner, and Mr. Loczy, of the geological department at the Vienna Museum. Mr. Easton states, presumably on the authority of Count Szechenyi, that the altitude of Si-ning-fu is 8,600 feet, and that of Tsing. hai, or Koko-Nor, 10,500 feet, while Lan-chow is about 5,000 feet above sea-level. The correct position of Si-ning is stated to be $36^{\circ} 33^{\prime} 32^{\prime \prime} \mathrm{N}$. lat., 102 $24^{\prime} 35^{\prime \prime} \mathrm{E}$. long. Some Germans had recently arrived at Lan-chow-fu to commence a woollen manufactory there for the Chinese, but Mr. Easton does not speak hopefully of their condition or prospects.

From a native Japanese paper we learn that the idea of opening Shimonoseki, on the Inland Sea, to foreigners has been abandoned, and that Nairi, in the province of Buzon, Kiushiu, has been selected as an open port in its place.

DURING his recent journey from the head of Lake Nyassa to Lake Tanganyika, Mr. James Stewart, C.E., who is now permanently attached to the Livingstonia mission of the Free Church of Scotland, visited four different tribes, of whom but little has previously been heard. The first was the Chungu tribe, on the lake-shore and inland up to the head of the Songwe valley; their country is described as good and cattle are numerous; iron, too, is abundant and much worked. This tribe, however, is by no means strong, owing to nearly every village being independent. The next tribe visited was the Anyamauga, whose country extends to the Mera River. To the west of them is Mambwe, under a young and intelligent chief, whose people are industrious ironworkers. In the hills round the south end of Lake Tanganyika are the Akandi tribes, all speaking different dialects. They are much harassed by the Bahemba. To the north, near the Fipa Mountains, the people are Basukuma, who are separated from the Anyamauga by the River Saisa. At Lake Hikwa, the name of which has hardly been heard of before the journeys of Messrs. Stewart and Thomson, and the position of which is not at present fully identified, the people are Abanda and Apimbwe, while the Chosi River is the boundary between the Mambwe and Babemba. We are glad to learn that $\mathrm{Mr}$. Stewart promises to send home immediately a map and section of his route, together with additional data, which cannot fail to be of interest from a geographical point of view.

ThE French Exploring Expedition for the Trans-Saharan Railway has left Wargla for the interior of Africa.

\section{THE METEOR SHOWER OF ҰANUARY 2}

FROM amongst the extensive number of annually recurring meteoric displays there are few comparable, either in point of richness or brilliancy, with the January meteors. The Leonids, Perseids, and Andromedes severally form showers of greater intensity at the epochs of their periodical returns, and there can be no question that the Perseids, as an annual phenomenon, stand unsurpassed, but with the exception of these special instances, perhaps none of the many streams of shooting stars deserve a higher place than that which heralds the opening of the year. The Lyrids, Orionids, and Geminids are entitled to be considered of equal importance as affording an annual spectacle of much interest, though the former system appears during its last few returns entirely to have lost the splendour which characterised its exhibitions in former years. The january zneteors, while thus meriting whatever significance is attached to a shower of the first order, have not, it must be admitted, been observed with half the diligence awarded to some other streams of similar nature. An explanation is probably to be found in the circumstance that it does not become thoroughly well visible until the morning hours. The radiant point situated at $23^{\circ} .5+5 r^{\circ} 3^{\circ}$ ( $15^{\circ}$ following $\eta$ Ursæ Majoris) in a region com paratively bare of stars, though never below our horizon, is yet, during the first half of the night, at a very low altitude, and thus its operations are limited, though not sufficiently so to cause the apparent extinction of the display. In the early evenings of January, 1879 and 1880 , it furnished many fine meteors ascending in long courses from the direction of the northern horizon, and appearing in sufficient numbers to cause remark amongst ordinary persons quite unaware of the progress of a notable star shower.

I have been speaking of this phenomenon as one of annual occurrence, but it is fair to conclude that it also possesses the elements of periodical fluctuations, as in the case of the Leonids and Perseids. Prof. Kirkwood, in a paper read before the American Philosophical Society on November 21, 1873, remarked upon this shower as one giving evidence of recurring brightness. He found, chiefly by the comparison of observations made during the present century, that its principal manifestations took place in the years 1825,1838 , and 1864 , from which he inferred a periodic time of thirteen years. This would have indicated a maximum in 1877 , but nothing of it was seen, though the shower has been very active since that period. Whether or not the investigations of Prof. Kirkwood have allowed the determination of its periodical maxima is a point to be settled by future observations. The history of the shower, as recorded in past years, is too incomplete to afford the materials for anything like a reliable estimate of the period of its revolution. Many times it has wholly escaped record, and even during its visible returns it is seldom witnessed with success. The state of the sky, the time and manner of observation, all affect the results to a considerable degree, and will often occasion apparent variations in the annual appearances of a shower which have no real existence. And it must be borne in mind that from the indefinite descriptions of former showers, it is sometimes impossible to ascribe a fair weight or to detach actual facts from the wild and often exaggerated notices of such phenomena.

Though no good correspondence has yet been detected between a cometary orbit and the orbit of this stream, it is none the less important that the precise centre of divergence of its meteors should be ascertained. Mr. Greg placed it at $232^{\circ}+49^{\circ}$ from an average of seven independent observations (see his catalogue of the radiant points and durations of meteor-showers in the B.A. Report, 1876), and found a closely adjoining shower of rather later date, which he regarded as distinct at $225^{\circ}+54^{\circ}$ for the period January $I$ to February 6 . The mean of the two is $228^{\circ} \cdot 5+5^{\circ} \cdot 5$, which presents a singularly near agreement with the centre of the shower as I have recently determined it from all the available observations of the radiant point, which have been compared together as follows :-

\section{Radiant Points of Fanuary Meteors.}

No. Epoch.

I, Dec. 15-Jan. I 5

2. Ian. $15-3 \mathrm{I}$

3. Jan. 2,1863

4. Jan. 2, 1864

5. Jan. 2,1867

6. Jan. 29-Feb. 6 ..

8. Jan. $2-7,1870 \ldots$

. Jan. $2-3,1872 \ldots$

I1. Jan. $1-15,1872$

12. Jan. $2-3,1873 \ldots$

13. Dec. 12 and 21, 1876

15. Jan. 20, 1877 ...

16. Jan. 2, 1878

17. Jan. 2, 1879

I8. Jan. 2,1880

19. Jan. 2,1880
7. Jan. 2-3 $\ldots$...

10. Jan. $2,1872 \quad \ldots$

I4. Jan. 4,1877
Observer.

E. Heis.

E. Heis.

S. Masters.

A. S. Herschel.

Herr Bornitz.

Greg and Zezioli.

Greg and Herschel.

G. L. Tupman.

A. S. Herschel.

T. Crumplen.

W. F. Denning. From the Italian Observations. T. W. Backhouse W. F. Denning. W. F. Denning. A. S. Herschel. W. F. Denning. W. F. Denning. H. Corder. H. Corder.
Mean position $=229^{\circ} \circ+51^{\circ} \cdot \eta$ from twenty observations, but the four positions distinguished by asterisks are not sufficiently accordant in epoch to be considered as certain displays of the 
same shower. Omitting them, the resulting mean from the remaining sixteen estimates is $=23^{\circ} .5+5^{1^{\circ}} 3$, which seems the most reliable centre for the true shower meteors of January 2, and nearly coincides with the radiant (No.8) abserved by Major Tupman in 1870 and that (No. I7) determined by the writer in 1879 .

That this meteor-cluster is comparatively seldom witnessed, arises from several causes. Cloudy weather offers a frequent impediment. The presence of the moon is also, in some years, a great drawback to successful observation. Moreover, the unfavourable situation of the radiant point in the evening hours considerably lessens the splendour of its display at the most convenient period for observation. In the clear, frosty mornings at the beginning of January the enthusiasm of amateur meteorobservers is seldom sufficient to keep them long out of doors. Yet a few interesting observations of this shower have been made during the past few years both in the morning and evening hours. In 1872 , on the night of January 2 , between 10.15 and 11.I5, Mr. W. H. Wood of Birminghain descried "a fine shower of bright meteors at the rate of twenty per hour for one observer ; 42 per cent. were from the usual radiant point. The meteors were of slow apparent speed, train-bearing and varicoloured." It was also well observed that year by Prof. Herschel and Mr. Crumplen at London. In $1873 \mathrm{Mr}$. Backhouse re-observed it in the morning of January 2 , between 5 and $7 \mathrm{~A} .3 \mathrm{M}$, when meteors were appearing at the estimated rate of thirty-seven per hour. During the three ensuing years this stream appears to have eluded observation. On the evening of January 4,1877 , it was slightly seen by the writer, and on the morning of January 2, 1878, 4 to 4.30 A.M., Prof. Herschel at Hawkhurst in Kent, noted seventeen of its meteors, indicating a very active though transient return of the shower, for a similar watch on the nights before and after its visible display revealed no sign of its appearance. It was seen again in 1879 by Prof. Herschel on the evening of January $I$ and morning of January 2 , and again with almost equal brightmess on the evening of January 2, producing eight or ten fine shooting-stars per hour in each watch. The shower was also recorded by the writer on the morning of January 2. Watching the sky between 6.15 A.M. and 6.35 A.M., no less than fourteen of its meteors were traced, though the greater part of the heavens was veiled in clouds.

The last return of the shower was witnessed by $\mathrm{Mr}$. Corder at Chelmsford on the evening of January 2. He maintained a watch of about $3 \frac{1}{4}$ hours between 6 and 10 P.M., seeing 66 shooting-stars, of which 48 were conformable to Quadrans (I 5 per hour). The radiant point appeared double at the points $232^{\circ}+55^{\circ}(36 \pm s)$ and $230^{\circ}+48^{\circ}(12 \pm \mathrm{s}$ ).

At Bristol the writer saw 25 meteors before 9.30 P. M., but frequent clouds intermpted regular observations-19 of the meteors observed diverged from the usual radiant point in Quadrans (at $\cdot 228^{\circ}+54^{\circ}$ \% Generally they were of more than ordinary brilliancy, with paths averaging $15^{1^{\circ}}$. Three bright meteors were registered as follows:-

$$
\begin{aligned}
& \text { Date. Time. Mag. } a \text { from } \delta \text { Path. } a \text { to } \delta
\end{aligned}
$$

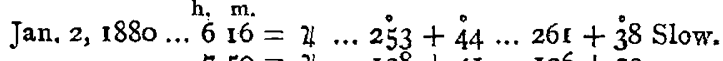

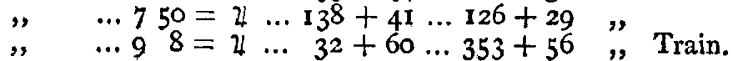

The third belonged to a radiant either in Perseus or Auriga. Mr. Corder appears to have obtained a duplicate observation of the second, and he gives the path as recorded by him from $248^{\circ}+70^{\circ}$ to $290^{\circ}+79^{\circ}$. The projected radiant from the combined observations is at $\mathbf{2 3 2}^{\circ}+5^{\circ}$. A smaller meteor recorded later (at 8.40) at both stations may also supply another accordance :-

$$
\left.\begin{array}{lll}
\text { Bristol } & \ldots & 308+73 \text { to } 358+54 \\
\text { Writtle } & \ldots & 328+52 \text { to } 343+41
\end{array}\right\} \begin{aligned}
& \text { Radiant point } \\
& \text { at } \gamma \text { Boütis. }
\end{aligned}
$$

The meteors of this special shower present some varieties of appearance which are, no doubt, to be explained by differences in the sensible position of the radiant point and by their apparent distances from that centre. In the evening the meteors traverse long flights with moderately slow motions, but in the morning hours their paths are short and the velocity seems increased. They are sometimes accompanied by trains and occasionally fain streaks remain on the courses, but they obviously belong to a different class to the swift, streak-leaving meteors of Perseus, Leo, and Orion.

There is a good radiant point not far south of that of the true
January meteors which the writer has seen several times in December and Jamary at $221^{\circ}+42^{\circ}$, and Zezioli traced it on January $19,1869,220^{\circ}+39^{\circ}$. The meteors are extremely swift and leave streaks, but the shower is of far less intensity than the Quadrantids of January 2, from which it may always be dissociated without much difficulty.

W. F. DENNING

\section{ON THE ASIATIC ALLIANCES OF THE FAUNA OF THE "CONGERIAN" DEPOSITS OF SOUTH-EASTERN EUROPE ${ }^{1}$}

THE molluscan fauna of Lake Baikal, lately made known by MM. Dybowski and Gertsfeld, is altogether different from the Palæarctic fauna, and is connected by many of its forms with the fresh-water fauna of the "Congerian" deposits of South-eastern Europe; thus it may be regarded as the northernmost outpost of a peculiar south-and east molluscan fauna. On the other hand the fauna of the Amoor region, quite Palrearctic on the whole, includes some members that approach North American types; while some Chinese Vivipare are conspicuously different from their Palæarctic congeners, and come near both to American forms and to those of the "Congerian" Paludinabeds. In R. P. Heude's " Conchyliologie fluviatile de la Province de Nanking," descriptions and figures are given of thirty-nine species of Unio, twenty of Anodonta, and five of Mycetopus. In Anderson's " Zoological Results of the two Expeditions to Western Yunnan," pl. lxxx., fig. 5, shows a gigantic knobbly-ribbed Vivipara, from Lake Tali, quite analogous to its Slavonian congeners. It is concluded that the Upper Miocene flora of Eastern Europe as well as the fauna of the Paludinaand Unio-beds, bears a Chino-Japanese rather than a North American character.

Besides the "Congerian" beds, with their abundance of Conger ia and Cardium, and the Paludinal deposits, characterised by the prevalence of Vivipara and Unio, a third zone is distinguishable among the upper freshwater tertiaries of Southeast Europe, namely, the "Melanopsis-marls," with ornate Melanopsides and abundant Neritince. The only known localities of these marls are the Balkan Peninsula and some of the Greek jslands. Even from this limited region we have already thirtysix species of Melanopsis and ten of Neritina, besides the eleven species of Melanopsis and nine of Neritina from the Southeast European "Congerian" deposits. The genus Neritina seems to be especially associated with islands. Lovel Reeve enumerates eight species from Tahiti, eleven from the Sandwich Islands, and thirty-nine from the Philippines; Gassies numbers forty from New Caledonia; Kobelt eleven from the Mediterranean region; about twenty species, nearly all highly ornate, belong to this region. L. Reeve mentions seven species from the West Indies, and ten from Central America. The two or three known North-American species are from the south frontier reoions; New Zealand numbers only two species. Extensive continental groups of strata are deficient in Neritina. The genus is wanting in Africa, East India, the Malayan Archipelago, Australia, and nearly the whole of America.

The species of Melanopsis found in the East-European deposits point, by their alliances, to the Mediterranean region; the Neritine rather to the Philippines and New Caledonia. This last island has many species of Melanopsis, and its fauna is somewhat analogous to that of the "Melanopsis-marls." In both cases a great number of species of both genera abound in a limited area; whilst the Mediterranean species are spread over a far wider region.

The fauna of the "Congerian" deposits is known to be closely allied to that of the Caspian; and the facts above-mentioned indicate that the alliances of the uppermost South-east European tertiaries are to be looked for within the Asio-Australian region, the supposed affinity to North America having been suggested in absence of a better knowledge of the Chino-Japanese fauna and flora

The total absence of the African type of elephant in the upper-terrestrial tertiaries of South Europe is very remarkable, especially as the mammalian fauna of that period has a decidedly African character. As to the flora of the tertiary period, Europe had a succession of Australian, Indian, Japanese, and Mediterranean floras, but never one of African character. The tertiary terrestrial and freshwater molluscs of Europe are analogons to those of New Caledonia, India, China, and Japan, but not to 1879 